\title{
Future uses of newer macrolides
}

\author{
JOHN SEGRETI, MD
}

$\mathrm{T}$ WO NEW MACROLIDE ANTIBIOTICS HAVE RECENTLY BECOME available for clinical use in the United States clarithromycin and azithromycin (which is an azalide). Only clarithromycin is currently available in Canada. Both of these new compounds have in vitro activity comparable to that of older macrolides such as erythromycin with the addition of activity against Haemophilus influenzae. In addition, both clarithromycin and azithromycin have been shown to have activity against uncommon and difficult to treat pathogens such as various protozoans, spirochetes, Helicobacter pylori and atypical mycobacteria.

\section{HELICOBACTER PYLORI}

$H$ pylori is the subject of growing interest. It is a spiral-shaped bacterium found in the antrum of most patients with inflammatory gastroduodenal lesions (1). It is generally accepted as a cause of chronic active gastritis. Its importance in the pathogenesis of duodenal ulcers remains unclear. Although $H$ pylori has not been established as an unequivocal cause of duodenal ulcers, there is persuasive evidence from treatment trials that eradication of $H$ pylori infection changes the natural history of peptic ulcer disease in patients with duodenal or gastric ulcers (2-4). There are currently no firm recommendations for antimicrobial therapy of $H$ pylori. When therapy is considered, it usually comprises bismuth subsalicylate and two antimicrobial agents such as tetracycline and metronidazole. Alternatively, ampicillin or amoxicillin has been used in place of tetracycline.
Although many antimicrobials appear effective against $H$ pylori, all attempts at monotherapy have been ineffective. In fact, there is usually marked resistance to the antimicrobial at the end of therapy. Clarithromycin and azithromycin have excellent in vitro activity against $H$ pylori (5). Clarithromycin is two to four times more active than erythromycin or azithromycin. Azithromycin has been studied as monotherapy of $H$ pylori. All pretherapy isolates were susceptible. However, 10 of the 12 post therapy isolates demonstrated high level resistance to azithromycin and one was moderately resistant. Therefore, azithromycin may be useful in combination therapy, but it should not be used as monotherapy for eradication of $H$ pylori. Clarithromycin appears to be the only drug studied which proved effective as monotherapy in eradication of $\mathrm{H}$ pylori (7). However, the study was very small and further clinical studies are indicated before clarithromycin can be recommended for therapy of eradication of $\mathrm{H}$ pylori.

\section{MYCOBACTERIUM SPECIES}

Clarithromycin and azithromycin have also been found to be more active in vitro than expected against several species of mycobacteria. This is extremely important since new drugs are desperately needed, especially for infections due to Mycobacterium avium complex (MAC). MAC is a ubiquitous organism and it is estimated that MAC may eventually infect most patients positive for the human immunodeficiency virus (HIV) $(8,9)$. Although there are no data that show that treatment of MAC will change the ultimate outcome in

Rush-Presbyterian-St Luke's Medical Center, Academic Facility. Chicago, Illinois, USA

Correspondence: Dr John Segreti, Assistant Attending Rush-Presbyterian-St Luke's Medical Center, 600 South Pauline, Suite 143, Academic Facility, Chicago, IL 60612, USA. Telephone (312) 942-5865, Fax (312) 942-2184 
acquired immunodeficiency syndrome (AIDS) patients, further studies are needed to determine if survival is improved. It is evident, however, that symptoms of MAC infection are improved with effective therapy and, therefore, the quality of life may be improved (10).

The ability of clarithromycin and azithromycin to concentrate in intracellular spaces where MAC exists make these drugs attractive choices. Indeed, both clarithromycin and azithromycin have been shown to be effective in the treatment of MAC infection in beige mice and human data are currently being compiled (11). A preliminary study by Dautzenberg et al demonstrated that clarithromycin had consistent activity against MAC in patients with MAC bacteremia (12). A study by Young et al (13) also demonstrated that azithromycin as a single oral agent was effective in AIDS patients with MAC bacteremia.

A recent randomized study evaluated the efficacy and safety of clarithromycin in the treatment of disseminated MAC (14). One hundred and eight patients were randomized to receive either 500,1000 or $2000 \mathrm{mg}$ of clarithromycin twice daily. An interim analysis of the first 72 patients demonstrated a significant log decline in colony-forming units of MAC in the blood over three months. In vitro resistance to clarithromycin developed in 16 of these patients. This study appears to indicate that clarithromycin is highly active against MAC bacteremia in patients with AIDS, but should not be used as a single agent because of the emergence of resistance.

There are currently studies underway to evaluate the use of clarithromycin and azithromycin in combination with other antimycobacterial agents for the treatment of disseminated MAC and as single agents for prophylaxis of MAC disease.

Another mycobacterium, Mycobacterium chelonae, is also of growing interest because of the marked antimicrobial resistance of this organism. Although a much less common infection than MAC, many therapies are ineffective for this organism. The therapies that are effective, such as amikacin, are potentially toxic. $M$ chelonae is very susceptible to clarithromycin, which is much more active than erythromycin or azithromycin. Wallace has reported a single drug protocol of patients with disseminated skin disease caused by $M$ chelonae treated with clarithromycin (15).

Approximately half the patients treated became asymptomatic and the other half had almost total resolution of their skin nodules. There is also reason to believe that clarithromycin and azithromycin may have potential use in the treatment of Mycobacterium leprae, an enormous problem worldwide. Both clarithromycin and azithromycin appear to be bactericidal when used as monotherapy in the treatment of leprosy in the mouse foot pad model and in preliminary human studies (1618).

Neither clarithromycin nor azithromycin have much activity against Mycobacterium fortuitum or Mycobac- terium tuberculosis (19). Therefore, it is unlikely that they will be of much benefit in the treatment of infections due to these organisms.

However, they may be of potential use in the treatment of other mycobacteria such as Mycobacterium kansasii, Mycobacterium marinum and Mycobacterium xenopi $(20,21)$.

\section{TOXOPLASMOSIS}

Toxoplasmosis is the most common opportunistic infection of the central nervous system in patients with AIDS. It appears that the incidence of cerebral toxoplasmosis is declining possibly due to trimethoprim-sulphamethoxazole prophylaxis for Pneumocystis carinii pneumonia (22). Clarithromycin and azithromycin, as well as another macrolide, roxithromycin, appear to be very active against Toxoplasma gondii in mouse models (23-25). The addition of minocycline to clarithromycin appears to be synergistic and in one study was superior to clarithromycin alone (26). In a small clinical trial of 13 AIDS patients with acute cerebral toxoplasmosis, clarithromycin in combination with pyrimethamine given for six weeks appeared to be well tolerated and very effective (27). Further studies are indicated.

\section{SPIROCHETES}

Clarithromycin and azithromycin have excellent in vitro activity against several spirochetes including Treponema pallidum, Borrelia burgdorferi and Leptospira species. Alder et al were able to demonstrate that clarithromycin had significant activity against $T$ pallidum in infected hamsters (28). Azithromycin has been used in patients with primary and early secondary syphilis with apparent success in preliminary studies (29).

Lyme disease is probably the most common tickborne infectious disease in the United States. It is due to infection with $B$ burgdorferi. This organism is exquisitely susceptible to a number of macrolides including erythromycin, azithromycin and clarithromycin. The rate of killing of $B$ burgdorferi is significantly better with azithromycin and clarithromycin than with erythromycin and beta-lactam antibiotics (30). Clarithromycin and azithromycin have been shown to be very effective in animal models of Lyme disease. In a limited human study, azithromycin given for seven days appeared to be as effective as amoxicillin given for 21 days for the treatment of Lyme disease (30).

\section{VIRULENCE-MODIFYING PROPERTIES}

Of additional interest is the ability of macrolides to modify bacterial virulence factors. There is evidence that azithromycin is able to inhibit production of Gramnegative exotoxins at subinhibitory concentrations. Molinari et al were able to demonstrate that azithromycin inhibited the enzymatic activities and pigment production of 10 strains of Pseudomonas aeruginosa (31). 
Erythromycin and clarithromycin were unable to modify expression of these virulence factors in the same strains. Different classes of antimicrobial agents have been shown to alter host defense mechanisms. Clarithromycin appears to improve chemotaxis and intracellular killing of polymorphonuclear leukocytes (32). Natural killer activity also appears to be increased in the presence of clarithromycin. Therefore, it appears that clarithromycin exerts a lasting stimulatory effect in some functions of cell-mediated immunity in healthy volunteers and ill patients.

\section{SUMMARY}

Both clarithromycin and azithromycin are likely to have extended uses in the future. Both newer macrolides clearly have a role in the therapy of disseminated MAC disease in AIDS patients. New macrolides may also prove to be effective in the treatment of other mycobacterial diseases, especially $M$ chelonae and $M$ leprae. It is likely they may also have a role in the treatment of toxoplasmosis, $H$ pylori and Lyme disease.

\section{REFERENCES}

1. Peterson WL. Helicobacter pylori and peptic ulcer disease. N Engl J Med 1991;324:1043-8.

2. Graham DY, Lew GM, Klein PD, et al. Effect of treatment of Helicobacter pylori infection on the long-term recurrence of gastric duodenal ulcer: A randomized, controlled study. Ann Intern Med 1992;1 16:705-8.

3. Coghlan JG, Humphries H, Dooley C, et al. Campylobacter pylori and recurrence of duodenal ulcers a 12-month follow-up study. Lancet 1987;ii:1109-11.

4. Marshall BJ, Warren JR, Blincow ED, et al. Prospective double-blind trial of duodenal ulcer relapse after eradication of Campylobacter pylori. Lancet 1988;ii:1437-41.

5. Hardy DJ, Hanson CW, Hensey DM, Beyer JM, Fernandes PB. Susceptibility of Campylobacter pylori to macrolides and fluoroquinolones. J Antimicrob Chemother 1988;22:631-6.

6. Glupczynski Y. Burette A. Failure of azithromycin to eradicate Campylobacter pylori from the stomach because of acquired resistance during treatment. Am J Gastroenterol 1990;85:98-9.

7. Graham DY, Opekun AR, Klein PD. Clarithromycin for the eradication of $H$ pylori. Abstracts of the 1991 Interscience Conference on Antimicrobial Agents and Chemotherapy, abst 954, p 258.

8. Chaisson RE, Moore RD, Richman DD, et al. Incidence and natural history of Mycobacterium avium-complex infections in patients with advanced human immunodeficiency virus disease treated with zidovudine. Am Rev Respir Dis 1992;146:285-9.

9. Nightingale SD, Byrd LT, Southern PM, et al. Incidence of Mycobacterium avium-intracellulare complex bacteremia in human immunodeficiency virus-positive patients. J Infect Dis 1992;165:1082-5.

10. Benson CA, Kessler HA, Pottage JC, Trenholme GT. Successful treatment of acquired immunodeficiency syndrome-related Mycobacterium avium complex disease with a multiple drug regimen including amikacin. Arch Intern Med 1991;151:582-5.

11. Klemens SP, DeStefano MS, Cynamon MH. Activity of clarithromycin against Mycobacterium avium complex infection in beige mice. Antimicrob Agents Chemother 1992;36:2413-7.

12. Dautzenberg B, Truffot C, Legris S, et al. Activity of clarithromycin against Mycobacterium avium infection in patients with the acquired immune deficiency syndrome: A controlled clinical trial. Am Rev Respir Dis 1991;144:564-9.

13. Young LS, Wiviott L, Wu M, Kolonoski P. Bolan R, Inderlied CB. Azithromycin for treatment of Mycobacterium avium intracellulare complex infections in patients with AIDS. Lancet 1991;338:1107-9.

14. Chaisson RE, Benson C, Dube M, et al. Clarithromycin therapy for disseminated Mycobacterium avium complex (MAC) in AIDS. Abstracts of the 1992 Interscience Conference on Antimicrobial Agents and Chemotherapy, abst 891, p 259.

15. Wallace RJ, Brown BA, Tanner D, Brennan PJ, Blahunka KS, Craft JC. An open trial of clarithromycin (CLAR) in therapy of (disseminated) cutaneous infection due to Mycobacterium chelonae subsp chelonae. Abstracts of the 1992 Interscience Conference on Antimicrobial Agents and Chemotherapy, abst 233. p 149.

16. Ji B, Jamet P, Bobin P, Grosset JH. Powerful bactericidal activities of clarithromycin and/or minocycline against $M$ leprae in man. The First International Conference on the Macrolides, Azalides, and Streptogramins. Santa Fe, New Mexico, 1992, abst 265, p 62.

17. Ji B, Jamet P, Perani EG, Bobin P, Grosset JH. Clarithromycin, a promising component of new combined regimens for the treatment of multibacillary leprosy. The First International Conference on the Macrolides, Azalides, and Streptogramins. Santa Fe, New Mexico, 1992, abst 266. p 62.

18. Gelber R, Siu P, Murray L, Tsang M, Prokocimer P, Blahunka K. Clarithromycin at very low levels and on intermittent administration consistently inhibits the growth of $M$ leprae in mice. The First International Conference on the Macrolides, Azalides, and Streptogramins. Santa Fe, New Mexico, 1992, abst 183, p 41.

19. Wallace RJ, Brown BA, Onyi GO, DeRosas V. Activities of four macrolides including clarithromycin (CL) against Mycobacterium fortuitum and Mycobacterium chelonae. The First International Conference on the Macrolides, Azalides, and Streptogramins. Santa Fe, New Mexico, 1992, abst 159, p 35.

20. Wallace RJ, Brown BA. Onyi GO. Activity of clarithromycin (CL) against slow-growing nontuberculous mycobacteria using a broth microdilution MIC system. The First International Conference on the Macrolides, Azalides, and Streptogramins. Santa Fe, New Mexico, abst 160, p 35.

21. Bonnet E, Debat-Zoguereh D, Gallais H. Cutaneous infection due to Mycobacterium marinum successfully treated with clarithromycin in a HIV-infected patient. Abstracts of the 1992 ICAAC, abst 1987, p 291.

22. Carr A, Tindall B, Brew BJ, et al. Low-dose trimethoprim-sulfamethoxazole prophylaxis for toxoplasmosis encephalitis in patients with AIDS. Ann Intern Med 1992;117:106-11.

23. Araujo FG, Guptill DR, Remington JS. Azithromycin, a macrolide antibiotic with potent activity against Toxoplasma gondii. Antimicrob Agents Chemother 1988:32:755-7.

24. Chan J, Luft BJ. Activity of roxithromycin (RU 28965), a macrolide, against Toxoplasma gondii infection in mice. Antimicrob Agents Chemother 1986;30:323-4. 
25. Chamberland S, Kirst HA, Current WL. Comparative activity of macrolides against Toxoplasma gondit demonstrating utility of an in vitro microassay. Antimicrob Agents Chemother 1991:35:903-9.

26. Derouin F, Caroff B, Chau F, Prokocimer P, Pocidalo JJ. Synergistic activity of clarithromycin and minocycline in an animal model of acute experimental toxoplasmosis. Antimicrob Agents Chemother 1992;36:2852-5.

27. Fernandez-Martin J, Leport C, Morlat P, Meyohas MC, Chauvin JP, Vilde JL. Pyrimethamine-clarithromycin combination for therapy of acute Toxoplasma encephalitis in patients with AIDS. Antimicrob Agents Chemother 1991;35:2049-52.

28. Alder J, Jarvis K, Mitten M, Clement J. Effective clarithromycin therapy of syphilis in hamsters. The First International Conference on the Macrolides, Azalides and Streptogramins. Santa Fe, New Mexico, abst 177, p 40.

29. Mashkilleyson AL, Gomberg MA. Azithromycin in patients with syphilis. The First International Conference on the Macrolides, Azalides and Streptogramins. Santa Fe, New Mexico, abst 260, p 60.

30. Luft BJ. Use of macrolides in the treatment of Lyme borreliosis. The First International Conference on the Macrolides, Azalides and Streptogramins. Santa Fe, New Mexico, abst 20, p 17.

31. Molinari G, Concia E, Bassetti D, Schito GC. Inhibition of Pseudomonas aeruginosa virulence factors by sub-inhibitory concentrations of azithromycin, a new macrolide. The First International Conference on the Macrolides, Azalides and Streptogramins. Santa Fe, New Mexico, abst 137, p 30.

32. Burgaleta C, Pernas M, Beltran JM, Herrero D. Effect of clarithromycin on phagocytosis and bactericidal activity of human polymorphonuclear leukocytes. The First International Conference on the Macrolides, Azalides and Streptogramins. Santa Fe, New Mexico, abst 176, p 39. 


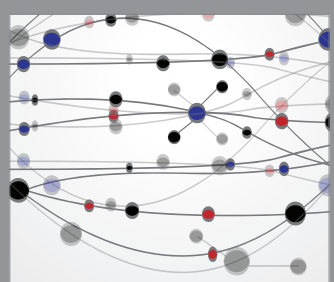

The Scientific World Journal
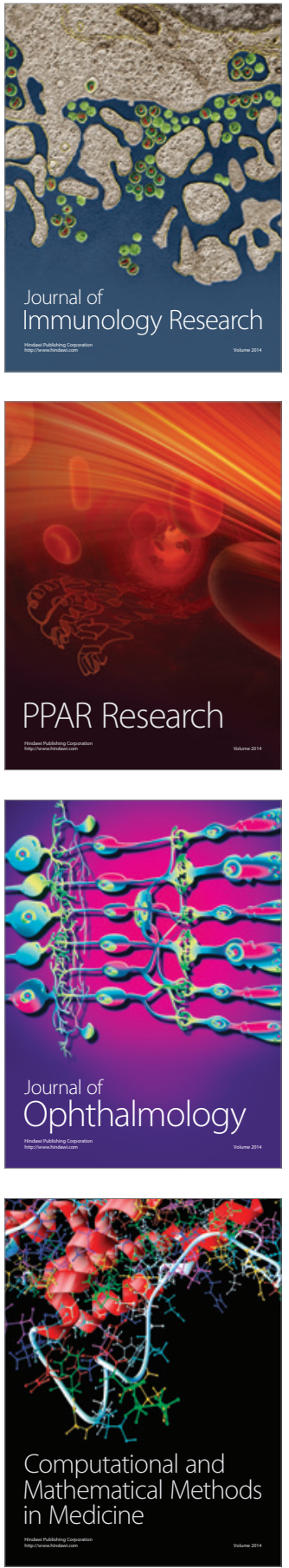

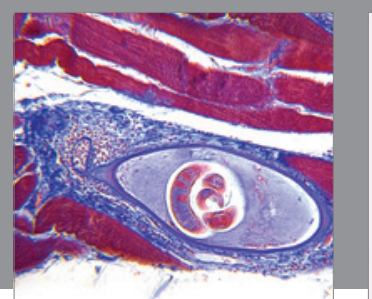

Gastroenterology Research and Practice

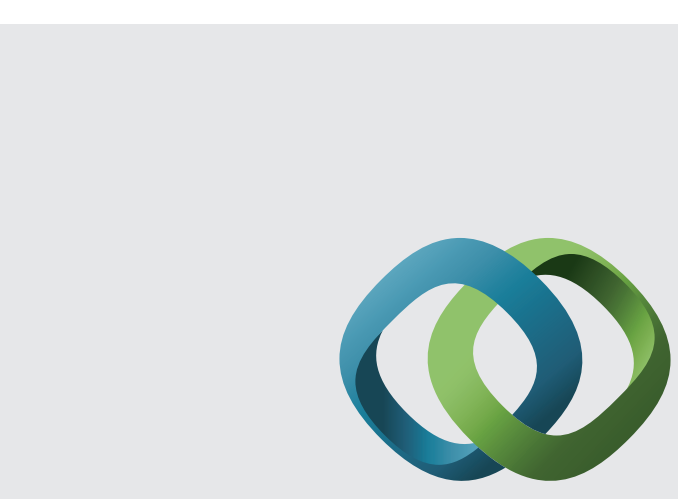

\section{Hindawi}

Submit your manuscripts at

http://www.hindawi.com
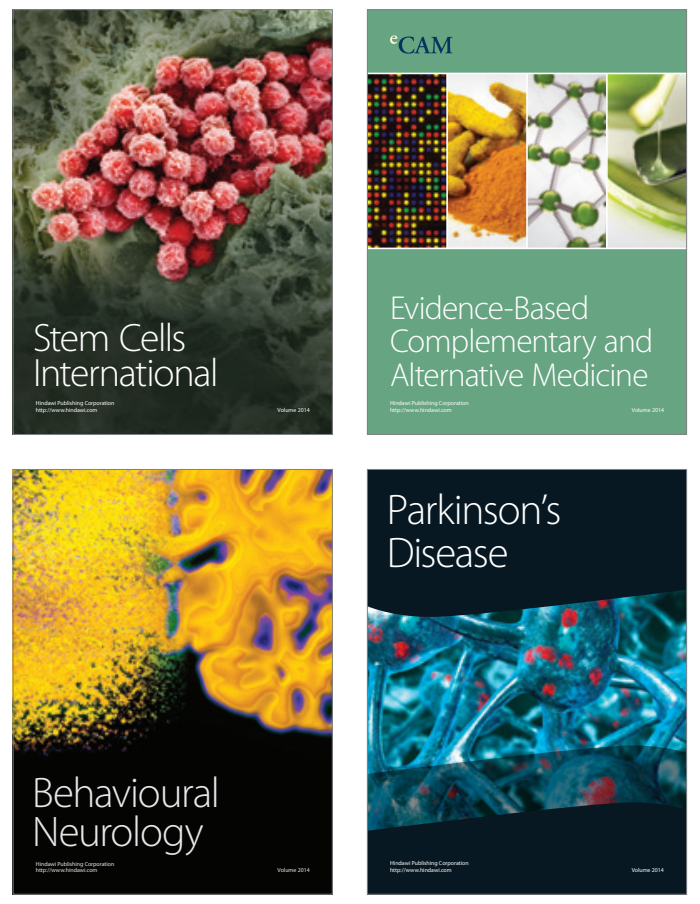
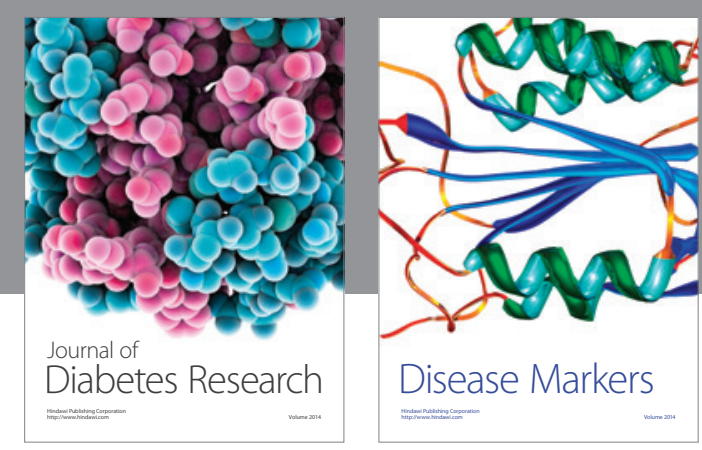

Disease Markers
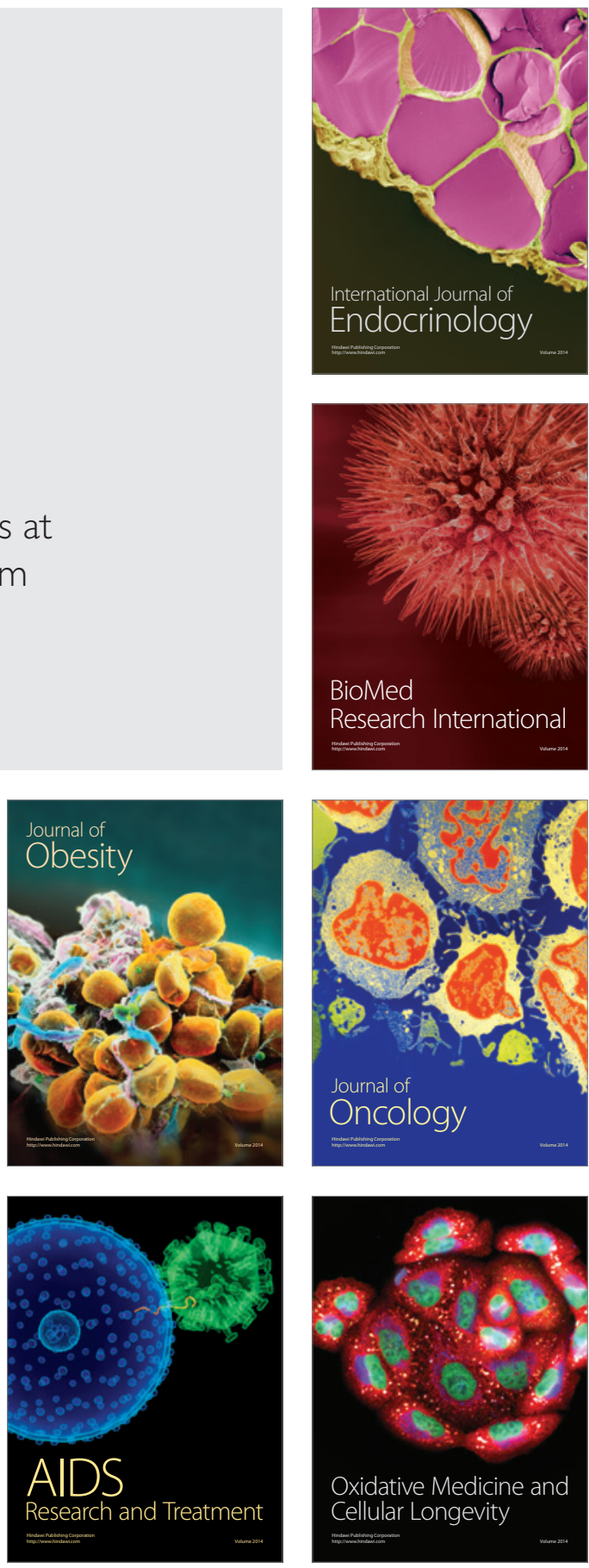